\title{
XXXV. Description of a method of fitting up in a portable form the Electric column lately invented by J. A. De Luc, Esq. Also an account of several experiments made with it
}

\section{B. M. Forster Esq.}

To cite this article: B. M. Forster Esq. (1810) XXXV. Description of a method of fitting up in a portable form the Electric column lately invented by J. A. De Luc, Esq. Also an account of several experiments made with it , Philosophical Magazine Series 1, 35:143, 205-210, DOI: 10.1080/14786441008563058

To link to this article: http://dx.doi.org/10.1080/14786441008563058

$$
\text { 曲 Published online: } 18 \text { May } 2009 .
$$

Submit your article to this journal ए

\section{山 Article views: 2}

Q View related articles ¿ 
Method of fitting up Mr. De Luc's Electric Column. 205

Ekeberg to be $7 \cdot 953$; and I have every reason to suppose their results correct, since a small fragment of the former appeared upon trial to be 5.87 , while a specimen of tantalite, weighed at the same time, was as much as $7 \cdot 8$. I should, however, observe, that the specific gravities of three other fragments borrowed for this purpose were not so high, that of one being $7 \cdot 65$, of another $7 \cdot 53$, and of 2 third so low as $7 \cdot 15$.

It is evident that no variation of mere proportion of the ingredients can account for an increase of specific gravity from $5 \cdot 918$ to $7 \cdot 953$, which are in the ratio of 3 to 4 ; for since columbite contains four fifths oxide, if the whole remaining one fifth part in weight of that oxide could be supposed added to the same bulk, without diminution of the quantities of iron and manganese, the specific gravity would not then cxceed $7 \cdot 1$; and even if a weight equal to one third of the whole were thus added, without increase of bulk, still the aggregate would not quite equal the heaviest tantalite in specific gravity; but on the contrary, the quantity of white oxide in this specimen certainly does not amount to six sevenths, and probably is not more than five sixths of the whole mass.

The only chemical difference, by which this circumstance could be explained, would be the state of oxidation, which my experiments cannot appreciate; but it may also arise in part from actual cavities in the mass of columbite, and in part from the state or mode of aggregation.

XXXV. Description of a Method of fitting up in a portable Form The Electric Column lately invented by J. A. Dr Luc, Esq. Also an Account of several Experiments made with it. By B. M. Fonster, Esq.

\section{To Mr. Tilloch.}

SrR, Having been informed that a row of galvanic plates had bcen consuructed without any fluid being interposed, and that it acted very sensibly on a gold-leaf electrometer, I formed one, of abont two hundred small circles of zinc, and the same number of blotting-paper and Dutch gold-leaf, the Dutch leaf being cemented on the paper with a solution of gum arabic; the blotting-paper was double, two pieces were gummed or pasted together before the Dutch leaf was put on. Through these circles, or plutes, a silken string was passed for connecting them together. This small instra- 
ment acted suffieiently powerfully on a very delicate goldleaf electrometer, to encourage me to make a row consisting of a greater number of plates. To the two hundred I added about three hundred more, using, instead of the Dutch metal, silver-leaf, and inserted the whole in a glass tube fitted up with brass caps, screws, and balls. The instrument thus fitted up may be called an Electric Rod. I have some of these rods with the plates not counected by a string through them; which, provided the glass tube is very nearly of the same diameter as the plates, may be the best way of placing them; but unless the tube fits accurately the other mode will probably be found preferable, as the plates can be more easily placed regularly.

The Dutch metal, or silver-leaf, may either be fastened to the paper with gum, or paste made over the fire with flour and water.

The following experiments were made with a rod of five hundred series of plates, - whether with the one in which were two hundred plates of Duch metal, or in which there was none, but silver-leaf instead, it is not necessary to mention.

21st Sept. 1809. One leaf of an electrometer made of Dutch metal kept flapping to and from the side of the glass many times, when connected with the electric rod.

The ends of the rod being placed upon two electrometers,- when the top of either of them was tonched, the electrometer at the opposite end diverged more immediately.

$22 \mathrm{~d}$ Sept. The rod was placed at the bottom of an electrometer; one leaf was attracted to the side and flapped several times.-This experiment shows that the electrie power of these piles or columns acts through a portion of air : I held the upper part of the electrometer in my hand during this experiment.

24 th Sept. A small piece of Dutch metal was attracted up to the ball at the zinc pole of the rod, and adhered to it.

4th Oct. A very light ivory needle, turning on a poimt (like a magnetic needle), was attracted by the rod; when a finger or a key was placed near one end of the needle, and the ball at the end of the rod also near the same end on the opposite side, the needle vibrated backwards and forwards. The needle was insulated, $I$ believe, by a piece of amber.

The needle, after having been touched by the silver-end pole, evidently receded from that pole; or, as it is commonly called, was repelled, having been charged 


\section{Method of fitting up Mr. De Luc's Electric Column. 201}

with the sane kind of electricity as that end of the rod pos sessed :- - the same effect was perceived when charged by the zinc pole.

One leaf of an electrometer (Dutch leaf) moved, when one of the balls on the rod was placed over the top, without being in contact with it.

15 th Oct. The ivory needle vibrated between the balls of two rods, one of which was at the zinc pole, the other at the opposite pole.

One column which I have made, consists of about 500 plates, each about $\frac{1}{4}$ th of an inch in diameter. I have put at the zinc end a piece of cork cut like the head of a snake or eel, and at the other end another to rescmble a tail. This columu may be called an artificial electric eel (Gymnotus electricus): it is not inserted in a tube like the others, a silken string runs through the centre of the plates, which may be drawn tight; then wound round a pin which is in the mouth, or may be loosened if desirable. This eel acts powerfully on the electrometers. The power appears to me to vary much more than that of the columns in tubes: provided the outside of these tubes be dry, I do not know that the strength of their electric power changes.

18 th Oct. Three rods, each of 500 series, were supported upon insulated stands, and a plate of copper suspended at the silver pole of the combined apparatus; another plate was placed under this, (as in the common electrical experiment of the dancing images,) one very small piece (or more) of tissue-paper was attracted up and fell down, and a little image of the same paper reared up, and once remained sus pencled to the upper plate, but I could not make it dance up and down.

22d Oct. One ball or both ? of Cavallo's pocket electrometer diverged, when three rods were combined ; the pithballs are on wires. With these three rods I could not perceive the metallic taste in the mouth, which is so perceptible even with a single piece of zinc and silver placed against the tongue. When the ball or balls ? of the electrometer moved, the opposite end of the apparatus was touched. A small pith-ball, suspended I believe with a single thread of a silkworm, vibrated between two fixed pith-balls, one of which was connected with the apparatus, the other communicated with the table.

23d Oct. A coated jar had a slight charge given to it with one of the electric rods. When the zinc pole charged the inside of the jar, that side gave signs of a minus state (as it is called), and the outside a plus state. This was shown 
by an electrometer, the leaves of which diverged when excited amber was holden near it, after it had received electricity from the inside, and converged when electrified from the outside of the bottle. From the usual effects of Galvanism the contrary might have been expected; that is, that the zinc end of the column would have produced the plus state, and the silver end the minus.

24th Oct. With three rod's combined, a small brass ball suspended by silk between two bells, vibrated between them, causing them to ring : the bells were suspended from the ends of the apparatus. The next day, 2 sih Oct. (the Jubilee day), having fixed on glass pillars two bells, and hung by silk a brass ball from the upper part of a piece of wire, I placed the bells in connexion with the ends of the combined apparatus, by means of bent wires laid on them : the apparatus and bells were left for near an hour, during which time the bells kept ringing, at times stopping for a short interval, then ringing again ; the clapper sometimes was seen to rest against one of them, then appeared to be disengaged by a person moving in the room. Whether the disengagement was always owing to some slight shaking of the table, or whether it was sometimes in consequence of the ball having acquired electricity, and then being repelled, I am not quite clear. It appears not improbable but that the weight of the clapper may be so adapted to the power of the apparatus, as to cause small bells to continue ringing for several years without intermission; if so, we shall have a machine which by those who do not consider the subject philosophically will be called a perpetual motion. How long the column will continue to produce the electric fituid cannot at present (or perbaps ever) be determined. The principal difficulty to be overcome, in order to keep the clapper in continual motion throughout the different seasons of the year, appears to be the want of a very accurate insulalion of the apparatus; for, if the glass tubes or the pillars which support them are damp, the current of the electric fiud will not pass along in the proper direction for the experiment.

29 th Nov. Five rods, each of 500 series, were combined; with these, two small bells kept ringing ond of for more than four hours, part of which time I was not in the room, so cannot tell how often they might have stopped: the ringing sometimes began again evidently not from any shake, but I imagine from the clapper having become electrifed, and then being (as it is usually called) repelled from the bell against which it rested. I placed three rods of 500 
series (insulated,) in a box, and brought wires from the ends of this combined apparatus, which I made communicare with two bells. I placed, on Tuesday 27 th February 1810, this apparaus in a closet, where I left it until Sunday 1 th March, the bells continuing to ring (as far as miv observations went) from the time they were put into the closet until that day: when they ceased. What was the cause of their stopping I do not know, but imagine it was owing to dampness. I cannot ascertain that they rang the whole time without stopping, but have no reason to believe otherwise. I intendid some months ago to have sent you the description of the above-mentioned apparatus with experiments, but deferred seading it on acconnt of Mr. De Luc's paper not bcing published, which he sent to the Royal Society in March, last year, and which contains a description of the elertric column and its properties. He hopes soon to publish it himself. In the mean time he has permitted me to communicate my account to you. I consider the invention of this column as the most important discovery in the science of electricity since that of the $V_{o l}$. taic pile, and do not doubt but that when Mr. De Luc gives his paper to the public, it will prove extremely interesting, and I have reason to believe it may lead to further discoveries which will be considered as very important in this branch of science.

\section{Description of the Figures.}

Fig. 1. A column of 500 series of plates about $\frac{5}{8}$ ths of an inch diameter, in a glass tube with brass caps, \&c. A A Brass caps, the ends of which screw on and off. BB Screws which pass through the caps into the tube, having a brass plate at the end for compressing the electric column.

CC Balls at the outer ends of the screws.

Fig. 2. One of the screws with a ball at the outer end, and a brass plate or circle at the other. A small hole is pierced in this plate, through which the silken string connecting the clectric column may pass.

Fig. 3. A smaller column (the plates of which are about $\frac{1}{4}$ th of an incis diameter, fitted up with a cork head and tail to represent an eel.

Fig. 4. Size of plates in larger column.

Fig. 5. Ditto of the smaller one.

Fig. 6. A combined apparatus, consisting of three rods resting on insulating stands, and having a wire projecting from each of the outer rods: these

Vol, 35. No. 143. March 1810.

$\mathrm{O}$ wires 
wires are for connecting the apparatus with electrometers, \&c.

Fig. 7. A couple of small bells supported on glass pillars, with a brass hall suspended from a wire, used as a clapper to ring the bells.

On Wednesday night, 14 th March, I put into a closet a couple of bells, communicating with the three rods above mentioned in a box; they then began to ring, and are now ringing:- how long they will continue so I cannot say; perhaps some change in the weather may soon occasion the clapper to cease vibrating.

$$
\text { I remain, \&c. }
$$

B. M. Forster.

Walthamstow, Essex, 20th March 1810.

XXXVI. On the comparative Infuence of Male and Female Parents on their Offspring. By Thomas ANDREW Knight, Esq., F.R.S. In a Leiter to the Right Hon. Sir Joseph Baniss, Bart. K.B. P.R.S.*

My Dear Sir, I have been engaged, during many years, in experiments on fruit-trees, of which the object has been to discover the best means of forming new varieties, that may be found better calculated for the climate of Britain than those at present cultivated, In this inquiry my efforts have been always most successful, when I propagated from the males of one variety and the females of another; and I was enabled, by the same means, to ascertain more accurately, than had previously been done, the comparative influence of the male and female parent on the character of the offspring. The analogy that subsists between plants and animals, in almost every thing which respects generation, induced me also to attend very minurely to similar experiments in which I engaged on some species of animals; and as the repetition of such experiments would necessarily require a very considerable space of time, and as the results seem to lead to conclusions that may be of public utility, I have thought the following account sufficiently interesting to induce me to address it to you.

Linnæus conceived, that the character of the male parent predominated in the exterior parts both of plants and animals; and the same opinions have been generally entertained by more modern naturalists. But the Swedish 